\title{
Predictive value of gene methylation for second recurrence following surgical treatment of first bladder recurrence of a primary upper-tract urothelial carcinoma
}

\author{
BAO GUAN* ${ }^{*}$ YUNCHAO XING* , GENGYAN XIONG* ${ }^{*}$, ZHENPENG CAO, DONG FANG, YIFAN LI, \\ YONGHAO ZHAN, DING PENG, LIBO LIU, XUESONG LI and LIQUN ZHOU \\ Department of Urology, Peking University First Hospital, Institute of Urology, Peking University, \\ National Urological Cancer Center, Beijing 100034, P.R. China
}

Received May 17, 2017; Accepted September 12, 2017

DOI: $10.3892 / \mathrm{ol} .2018 .8498$

\begin{abstract}
The clinical relevance of aberrant DNA promoter methylation is being increasingly recognized in urothelial carcinoma. The present study was conducted to explore the methylation status of patients with upper-tract urothelial carcinoma (UTUC) who experienced bladder recurrence, and to evaluate the predictive value of gene methylation for second bladder recurrence and tumor progression. A total of 85 patients with primary UTUC, who experienced bladder recurrence after radical nephroureterectomy, were enrolled between January 2001 and December 2013. Using methylation-sensitive polymerase chain reaction, the promoter methylation statuses of 10 genes were analyzed in the bladder tumor specimens. Among the patient group, 32 patients experienced second bladder recurrence, and bladder progression was detected in 16 . With the exception of BRCA1, the methylation rate of the majority of genes tended to gradually increase to varying extents with the number of recurrences; a smaller proportion of primary tumors exhibited gene methylation when compared with the first recurrent tumors and second recurrent tumors. Univariate and multivariate Cox regression analyses revealed that unmethylated GDF15 [hazard ratio $(\mathrm{HR})=0.36 ; 95 \%$ confidence interval $(\mathrm{CI})$, 0.14-0.92] and methylated VIM $(\mathrm{HR}=2.91 ; 95 \%$ CI, 1.11-7.61) in the first recurrent bladder tumor, as well as male gender ( $\mathrm{HR}=2.28 ; 95 \% \mathrm{CI}, 1.06-4.87)$, first recurrence interval $<8$ months $(\mathrm{HR}=2.34$; 95\% CI, 1.15-4.78) and primary UTUC
\end{abstract}

Correspondence to: Professor Xuesong Li or Professor Liqun Zhou, Department of Urology, Peking University First Hospital, Institute of Urology, Peking University, National Urological Cancer Center, 8 Xishiku Street, Xicheng, Beijing 100034, P.R. China

E-mail: pineneedle@sina.com

E-mail: zhouliqunmail@sina.com

*Contributed equally

Key words: epigenetic biomarkers, recurrence, promoter methylation, predictive model, upper-tract urothelial carcinoma tumor size $\geq 5 \mathrm{~cm}(\mathrm{HR}=3.48$; 95\% CI, 1.43-8.45) were independent risk factors for a second bladder recurrence after surgery for the first bladder recurrence; the Harrell's concordance index (c-index) for the related nomogram was 0.71 (95\% CI: 0.61-0.81). Furthermore, methylated $\mathrm{CDH} 1(\mathrm{HR}=2.91$; 95\% CI, 1.08-7.77) and VIM $(\mathrm{HR}=4.91 ; 95 \% \mathrm{CI}, 1.11-21.7)$ in the first recurrent bladder tumor, male gender $(\mathrm{HR}=3.6 ; 95 \% \mathrm{CI}, 1.1-11.73)$, and primary tumor stage T2-T4 $(\mathrm{HR}=4.57 ; 95 \% \mathrm{CI}, 1.22-17.13)$, multifocality $(\mathrm{HR}=3.64 ; 95 \% \mathrm{CI}, 1.19-11.16)$ and size $\geq 5 \mathrm{~cm}$ (HR=3.1; 95\% CI, 1.91-10.54) for the primary UTUC were considered to be predictors of tumor progression; the c-index for the nomogram was 0.88 (95\% CI, 0.69-0.92). The present findings demonstrated that promoter methylation of cancer-related genes was frequently observed in patients with urothelial carcinoma, and that the gene methylation rate of certain genes tended to gradually increase with the number of bladder recurrences. This may be used as a predictive factor for a second bladder recurrence and tumor progression after the surgical treatment of the first bladder recurrence.

\section{Introduction}

Upper-tract urothelial carcinoma (UTUC), including ureteral and renal pelvic carcinoma, is a relatively uncommon disease that accounts for $5-10 \%$ of cases of urothelial carcinoma $(1,2)$. Radical nephroureterectomy (RNU) with excision of the bladder cuff is the gold-standard treatment for UTUC; however, due to the frequent multifocal nature of urothelial carcinomas, $22-47 \%$ of all primary UTUC patients experience bladder recurrence after RNU $(3,4)$. Moreover, the patients who experience bladder tumor recurrence often require more than one transurethral resection of the bladder tumor (TURBT), which leads to increased suffering of the patient. Multiple bladder recurrences treated with repeated TURBT may significantly reduce a patient's quality of life, and some patients must undergo radical cystectomy for bladder tumor progression during the repeated recurrences. A number of previous studies have reported that the risk factors for bladder recurrence include tumor multifocality, tumor site and patient gender (5-7). However, a lack of effective markers remains a challenge with regard to the prediction of bladder recurrence. It is necessary to 
increase the amount of available data addressing second recurrence after surgery for a first bladder recurrence, in order to establish novel prognostic factors and predictive models.

As a major epigenetic mechanism in humans, gene methylation plays an important role in the development, progression and prognosis of various types of carcinoma (8-10). Our previous study evaluated the methylation statuses of 10 selected genes with regard to their prognostic value for bladder recurrence of a primary UTUC treated with RNU, and found that gene methylation was a common status and could predict bladder recurrence in UTUC patients (11). In the present study, to continue our previous research, we collected data from patients who experienced bladder recurrence from a primary UTUC database, and evaluated the predictive value of gene methylation and clinical factors for subsequent outcomes after the surgical treatment of a first bladder recurrence following primary UTUC treated with RNU.

\section{Patients and methods}

Patient selection. This was a retrospective study. All patients with primary UTUC in our database had been diagnosed with UTUC and had undergone RNU at Peking University First Hospital (Beijing, China) between January 2001 and December 2013. None of the patients had received neoadjuvant chemotherapy prior to RNU. Following the exclusion of patients with a previous history of bladder cancer, 318 patients remained in the database. Among these 318 primary UTUC patients, 110 experienced bladder recurrence, of which 25 patients were excluded: 9 in whom the first recurrent bladder tumor was stage T0 or Tis, 6 who were lost to follow-up, and 10 for whom paraffin specimens could not be obtained. A total of 85 patients were included in the final analysis. All patients provided written informed consent.

Diagnosis and treatment. The diagnosis, treatment and pathological examination of primary UTUC samples were performed as described in our previous study (11). Bladder recurrence of UTUC was diagnosed by cystoscopy with biopsy, and TURBT was performed according to the standard procedure. Radical cystectomy was performed for recurrent bladder tumors where indicated due to tumor progression; otherwise, repeated TURBT was performed. All patients received one immediate instillation of Mitomycin C or epirubicin within $24 \mathrm{~h}$ after TURBT.

All resected specimens were reviewed by two senior pathologists who were blinded to the personal data of the patients. Tumor stage was evaluated according to the 2002 UICC TNM classification of malignant tumors, and tumor grade was assessed according to the 1973 WHO classification (12). The time between primary UTUC and the first bladder recurrence was defined as the first recurrence interval.

Methylation analysis of gene promoters. The methylation statuses of 10 selected genes (ABCC6,BRCA1, CDH1, GDF15, HSPA2, RASSF1A, SALL3,THBS1,TMEFF2, VIM) were evaluated in 117 bladder tumors ( 85 from a first recurrence, and 32 from a second recurrence). DNA extraction, bisulfite transformation and gene methylation status were evaluated according to the procedures described in our previous study (11). The methylation statuses of the genes between urothelial tumors and normal tissues were not compared as all genes investigated in this study have been validated to have a low methylation rate in normal tissues (13-16).

Postoperative follow-up. The patients were followed-up every 3 months for the first 2 years after surgery, and annually thereafter at our institution. The follow-up consisted of physical examination, urinalysis, cytology, chest X-ray, ultrasound or CT/MRI, and cystoscopy. Second bladder recurrence and tumor progression were used as the endpoints in this study. Tumor progression was defined as the presence of a pathologically confirmed, muscle-invasive tumor (above stage T2) in the bladder during follow-up. Patients who were still alive without a second recurrence or tumor progression were censored at the last follow-up, and the survival time was censored at death during follow-up.

Statistical analysis. $\chi^{2}$ tests were used to compare categorical variables. Binary logistic regression was used to evaluate methylation status with respect to tumor stage and grade. The second bladder recurrence-free survival (BRFS) rate and progression-free survival (PFS) rate after the surgical treatment of the first bladder recurrence were evaluated by the Kaplan-Meier method. Variables influencing BRFS and PFS were compared using Cox proportional hazards regression models. Variables with $\mathrm{P}<0.05$ on univariate analysis were also assessed by multivariate analysis. Multivariate Cox regression coefficients were then used to generate nomograms to predict the 6-, 12-, 24- and 36-month BRFS and PFS rates, and Harrell's concordance index (c-index) was used to quantify the discrimination ability of these nomograms, and calibration plots were generated to explore the performance of the nomograms. All statistical analyses were performed using IBM SPSS version 20.0 and $\mathrm{R}$ version 3.2.0. Two-sided $\mathrm{P}$-values $<0.05$ were considered to indicate statistical significance.

\section{Results}

Overall results of clinical follow-up. The characteristics of the 85 patients with primary UTUC and first bladder recurrence are presented in Table I. Of the 85 patients, 42 (49.4\%) were female and $43(50.6 \%)$ were male, and the median age was 67 years (range, 46-82 years). The median follow-up time was 51 months (range, 5-161 months). During follow-up, there were 31 mortalities (36.5\%), of which 29 were due to cancer, and a total of 32 patients $(37.6 \%)$ developed second bladder recurrence. The median interval between RNU and the first bladder recurrence was 15 months (range, 2-98 months) and the median interval between the first and second bladder recurrences was 31 months (range, 2-126 months). A total of 16 patients experienced tumor progression during follow-up. The median interval between the first bladder recurrence and tumor progression was 41 months (range, 4-126 months) Of the 16 patients with tumor progression, 8 received radical cystectomy and 8 received TURBT.

Gene methylation status and oncological outcomes. The methylation rates of the 10 selected genes in primary UTUC, and first and second recurrent bladder tumors are summarized in Table II and Fig. 1. GDF15 (primary, 50.6\%; 
Table I. Characteristics of primary UTUC and first bladder recurrence tumor of all the 85 patients.

\begin{tabular}{lc}
\hline $\begin{array}{l}\text { Clinicopathologic } \\
\text { characteristics }\end{array}$ & $\begin{array}{c}\text { Median (range) } \\
\text { or no. }(\%)\end{array}$ \\
\hline
\end{tabular}

\begin{tabular}{ll}
\hline Age & $67(46-82)$ \\
Gender & \\
Female & $42(49.4)$ \\
Male & $43(50.6)$ \\
No. of subsequent recurrence &
\end{tabular}

No. of subsequent recurrence

1

2

85 (100)

$15(17.6)$

$10(11.8)$

7 (8.2)

$\geq 4$

$69(81.2)$

$16(18.8)$

$29(34.1)$

$2(2.4)$

Cancer-specific death

Other death

Characteristics of primary UTUC

Tumor stage

Ta, T1

$31(36.5)$

T2

37 (43.5)

17 (20.0)

Tumor grade

G1

G2

G3

55 (64.7)

$26(30.6)$

Tumor size

Small $(<5 \mathrm{~cm})$

$76(89.4)$

$9(10.6)$

Tumor architecture

Papillary tumor

$72(84.7)$

Sessile tumor

Tumor location

Renal pelvis

Ureter

$50(58.8)$

35 (41.2)

Tumor multifocality

Absent

60 (70.6)

Present

25 (29.4)

Characteristics of first bladder recurrence tumor

Tumor stage

Ta

45 (53.6)

T1

35 (41.7)

5 (4.7)

Tumor grade

G1

$\mathrm{G} 2$

$59(70.2)$

G3
Table I. Continued.

Clinicopathologic
characteristics

Median (range) or no. (\%)

$\begin{array}{lr}\text { First recurrence interval } & \\ \text { Long }(\geq 8 \text { months) } & 59(69.4) \\ \text { Short }(<8 \text { months) } & 26(30.6) \\ \text { Renal function } & \\ \text { eGFR } \geq 30 \mathrm{ml} / \mathrm{min} & 76(89.4) \\ \text { eGFR }<30 \mathrm{ml} / \mathrm{min} & 9(10.6)\end{array}$

UTUC, upper-tract urothelial carcinoma; eGFR, estimated glomerular filtration rate.

first recurrence, $65.9 \%$; second recurrence, $75 \%$ ) and VIM (primary, 58.8\%; first recurrence, 60\%; second recurrence, $75 \%$ ) had the highest methylation rates. With the exception of $B R C A 1$, all genes showed a higher methylation rate in the second recurrent tumors compared with the first recurrent tumors, and in the first recurrent tumors compared with the primary UTUC. The associations between gene promoter methylation statuses and pathological tumor characteristics are shown in Table III. Univariate analysis showed that methylated statuses in the ABCC6, BRCA1, CDH1, GDF15, HSPA 2 and RASSF1A promoters were significantly associated with $\mathrm{pT} 1 / \mathrm{T} 2$ stage in the first bladder recurrence. However, on binary logistic regression analysis, after adjusting for clinical and pathological factors, promoter methylation status in any of the 10 genes in the first recurrent bladder tumor was not associated with T1/T2 stage or grade 3 malignancy.

The univariate and multivariate analyses of prognostic significance are shown in Table IV. The 12-, 24-, 36- and 60-month BRFS rates were 75.8, 66.6, 63.6 and 58.2\%, respectively. On multivariate analysis, unmethylated GDF15 [hazard ratio $(\mathrm{HR})=0.36 ; 95 \%$ confidence interval $(\mathrm{CI}), 0.14-0.92]$ and methylated VIM $(\mathrm{HR}=2.91 ; 95 \% \mathrm{CI}, 1.11-7.61)$ in the first recurrent bladder tumor, as well as male gender $(\mathrm{HR}=2.28$; 95\% CI, 1.06-4.87), first recurrence interval $<8$ months $(\mathrm{HR}=2.34 ; 95 \% \mathrm{CI}, 1.15-4.78)$ and primary tumor size $\geq 5 \mathrm{~cm}$ ( $\mathrm{HR}=3.48$; 95\% CI, 1.43-8.45) were independently associated with second bladder recurrence. The 12-, 24-, 36- and 60-month PFS rates were 93.9, 84.6, 81.5 and 79.7\%, respectively. Methylated $\mathrm{CDH} 1 \mathrm{HR}=2.91 ; 95 \% \mathrm{CI}, 1.08-7.77)$ and VIM $(\mathrm{HR}=4.91 ; 95 \% \mathrm{CI}, 1.11-21.7)$ in the first recurrent bladder tumor, male gender $(\mathrm{HR}=3.6 ; 95 \% \mathrm{CI}, 1.1-11.73)$, and primary tumor stage T2-T4 $(\mathrm{HR}=4.57 ; 95 \% \mathrm{CI}, 1.22-17.13)$, multifocality $(\mathrm{HR}=3.64 ; 95 \% \mathrm{CI}, 1.19-11.16)$ and size $\geq 5 \mathrm{~cm}$ $(\mathrm{HR}=3.1 ; 95 \% \mathrm{CI}, 1.91-10.54)$ were significantly associated with tumor progression on multivariate analysis.

Predictive model for BRFS and PFS. The nomogram for predicting the probability of BRFS following surgery for first bladder recurrence is illustrated in Fig. 2A, and the c-index of this multivariate model was 0.71 (95\% CI: 0.61-0.81). The calibration plots at 1-year and 3-year follow-up for the nomogram are shown in Fig. 2B and C, respectively. The nomogram for predicting the probability of PFS after surgery for first 
Table II. The gene methylation rate of primary UTUC, the first bladder recurrence tumor and second bladder recurrence tumor.

\begin{tabular}{|c|c|c|c|}
\hline $\begin{array}{l}\text { Gene } \\
\text { promoter }\end{array}$ & $\begin{array}{c}\text { Primary } \\
\text { UTUC } \\
(\%)\end{array}$ & $\begin{array}{c}\text { First } \\
\text { bladder } \\
\text { recurrence } \\
(\%)\end{array}$ & $\begin{array}{c}\text { Second } \\
\text { bladder } \\
\text { recurrence } \\
(\%)\end{array}$ \\
\hline Total no. & 85 & 85 & 32 \\
\hline \multicolumn{4}{|l|}{$A B C C 6$} \\
\hline Unmethylated & $75(88.2)$ & $61(71.8)$ & $22(68.8)$ \\
\hline Methylated & $10(11.8)$ & $24(28.2)$ & $10(31.3)$ \\
\hline \multicolumn{4}{|l|}{$B R C A 1$} \\
\hline Unmethylated & $70(82.4)$ & $55(64.7)$ & $26(81.3)$ \\
\hline Methylated & 15 (17.6) & $30(35.3)$ & $6(18.8)$ \\
\hline \multicolumn{4}{|l|}{$\mathrm{CDHI}$} \\
\hline Unmethylated & $74(87.1)$ & $64(75.3)$ & $24(75.0)$ \\
\hline Methylated & $11(12.9)$ & $21(24.7)$ & $8(25.0)$ \\
\hline \multicolumn{4}{|l|}{ GDF15 } \\
\hline Unmethylated & $42(49.4)$ & $29(34.1)$ & $8(25.0)$ \\
\hline Methylated & $43(50.6)$ & $56(65.9)$ & $24(75.0)$ \\
\hline \multicolumn{4}{|l|}{ HSPA2 } \\
\hline Unmethylated & $62(72.9)$ & $38(44.7)$ & $12(37.5)$ \\
\hline Methylated & $23(27.1)$ & $47(55.3)$ & $20(62.5)$ \\
\hline \multicolumn{4}{|l|}{ RASSF 1A } \\
\hline Unmethylated & $70(82.4)$ & $69(81.2)$ & $26(81.2)$ \\
\hline Methylated & $15(17.6)$ & $16(18.8)$ & $6(18.8)$ \\
\hline \multicolumn{4}{|l|}{ SALL3 } \\
\hline Unmethylated & $62(72.9)$ & $48(56.5)$ & $16(50.0)$ \\
\hline Methylated & $23(27.1)$ & $37(43.5)$ & $16(50.0)$ \\
\hline \multicolumn{4}{|l|}{ THBSI } \\
\hline Unmethylated & $63(74.1)$ & $60(70.6)$ & $16(50.0)$ \\
\hline Methylated & $22(25.9)$ & $25(29.4)$ & $16(50.0)$ \\
\hline \multicolumn{4}{|l|}{ TMEFF2 } \\
\hline Unmethylated & $57(67.1)$ & $49(57.6)$ & $18(56.3)$ \\
\hline Methylated & $28(32.9)$ & $36(42.4)$ & $14(43.8)$ \\
\hline \multicolumn{4}{|l|}{$V I M$} \\
\hline Unmethylated & $35(41.2)$ & $34(40.0)$ & $8(25.0)$ \\
\hline Methylated & $50(58.8)$ & $51(60.0)$ & $24(75.0)$ \\
\hline
\end{tabular}

UTUC, upper-tract urothelial carcinoma.

bladder recurrence is illustrated in Fig. 3A, and c-index of this multivariate model was 0.88 (95\% CI: 0.69-0.92). The calibration plots at 1-year and 3-year follow-up for the nomogram are shown in Fig. 3B and C, respectively.

\section{Discussion}

UTUC is a relatively rare cancer. Approximately $60 \%$ of UTUCs are invasive at diagnosis, compared with $15-25 \%$ of

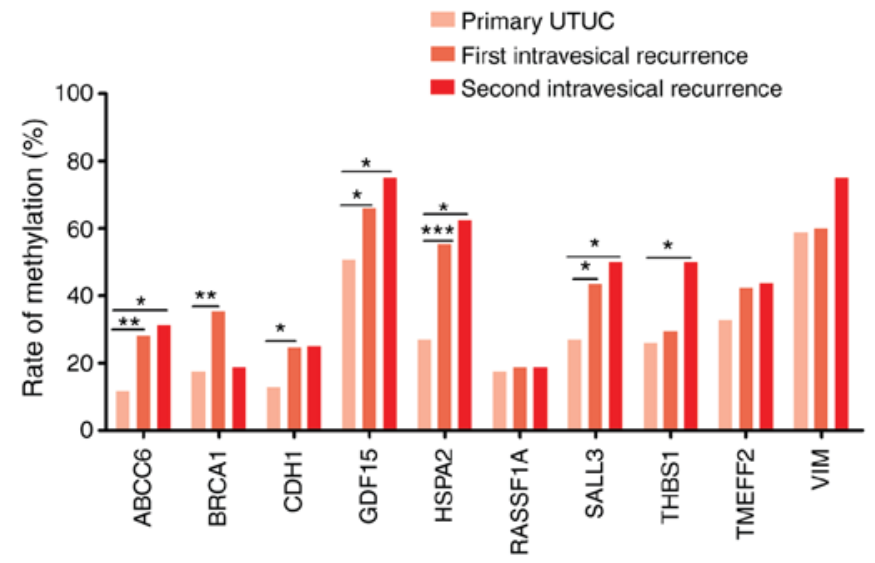

Figure 1. Gene methylation rates in primary UTUC, first recurrent bladder tumor and second recurrent bladder tumor. ${ }^{*} \mathrm{P}<0.05,{ }^{* *} \mathrm{P}<0.01,{ }^{* * * *} \mathrm{P}<0.001$. UTUC, upper-tract urothelial carcinoma

all bladder tumors, and thus this disease has a comparatively poor prognosis (6). The European Association of Urology Guidelines reviewed several published studies and reported that four different nomograms are available for predicting survival rates postoperatively, based on standard pathological features (17-20). Recently, several papers reported a number of clinicopathological features and gene promoter methylation statuses of UTUC patients that might affect the probability of bladder recurrence, including patient gender, smoking status, tumor multifocality, surgical management, and GDF15 and RASSF1A promoter methylation (11,21-23). However, although a few papers have addressed the clinical course after the first bladder tumor relapse, none of the studies has provided any significant recommendation concerning bladder surveillance. In the present study, we collected data from UTUC patients who experienced bladder recurrence following a primary UTUC treated with RNU, and evaluated the prognostic value of gene promoter methylation and clinical factors for the subsequent outcomes, including repeated recurrence and progression after TURBT for the first bladder recurrence.

DNA methylation is an important biochemical process that is involved in the normal development of higher organisms. A family of DNA methyltransferases transfer a methyl group from $S$-adenosyl methionine to the fifth carbon of a cytosine residue to form 5-methylcytosine, thereby catalyzing DNA methylation. This modification can be inherited through cell division (24). Beside its involvement in normal development in human beings, DNA methylation is frequently implicated in the onset or course of cancer due to its roles in many other regulatory processes. Several studies have reported that aberrant promoter methylation at several gene loci was associated with bladder urothelial carcinoma (13,25-27). As bladder urothelial carcinoma and UTUC display genomic and clinical similarities, we selected 10 genes (ABCC6, BRCA1, CDH1, GDF15, HSPA2, RASSF1A, SALL3, THBS1,TMEFF2 and VIM) with a high frequency of methylation in bladder urothelial carcinoma and evaluated their methylation statuses in UTUC and their associations with clinical outcomes.

According to our results, gene methylation is common in recurrent bladder tumors. Compared with our previous study that focused on primary UTUC, we found that gene methylation rate exhibits a significant increasing trend with 
the development and recurrence of UTUC (primary UTUC to first bladder recurrence to second recurrence); this partly confirmed the 'intraluminal seeding and implantation' hypothesis, which is the classic mechanism for bladder recurrence of primary UTUC $(28,29)$. Our results indicated that promoter methylation in 10 genes in the first recurrent bladder tumor was not associated with pT1/T2 and grade 3 malignancy. However, a former study (11) showed that certain epigenetic biomarkers of primary UTUC were significantly associated with tumor malignancy (pT3/T4, tumor grade 3 and positive lymph node metastasis). Therefore, we suggested that the tumor stage and grade of the first bladder recurrence could not be predicted by the gene methylation status of the recurrent bladder tumor, and it was difficult to explain this interesting phenomenon with existing theories.

After adjusting for clinical and pathological factors, multivariate analysis showed that male gender, a short interval between initial RNU and first bladder recurrence, unmethylated GDF15 and methylated VIM in the first recurrent bladder tumor, and a primary UTUC tumor size $>5 \mathrm{~cm}$ were independently associated with repeated bladder relapse after surgery for the first bladder recurrence. GDF15 encodes a divergent member of the transforming growth factor (TGF)- $\beta$ superfamily, whose members are required for normal development, differentiation, and tissue homeostasis. The anti-tumorigenic activity of GDF15 has been suggested to be due to the association between GDF15 overexpression and tumor growth arrest and increased apoptosis (25). Thus, we hypothesized that this anti-tumorigenic activity reduced bladder recurrence. Male gender, methylated $C D H I$ and VIM in the first recurrent bladder tumor, and high tumor stage, large tumor size and multifocality of primary UTUC were independently associated with bladder tumor progression. VIM, CDHI and GDF15 have been confirmed to be upregulated by promoter demethylation. VIM methylation has been found to be more frequent in bladder urothelial carcinoma and UTUC, but rare in normal tissue, and may therefore be useful as a novel diagnosis and detection method in urothelial cancer. Downregulation of VIM has also been associated with increased tumor invasion, progression, epithelial to mesenchymal transition (EMT) and poor prognosis in various types of tumor (30-34). Monteiro-Reis et al (31) suggested that during early upper urinary tract carcinogenesis, the VIM promoter is progressively methylated and the gene is kept silenced, as in normal urothelium; by contrast, in a subset of UTUCs, methylation is decreased, allowing for aberrant vimentin expression, due to stimuli leading to EMT. As a consequence, these tumors may be more prone to local invasion and systemic dissemination, thus fostering disease progression and increasing recurrence. In previous studies, $\mathrm{CDH} 1$ methylation was found to be more frequent in colorectal cancer than in adjacent non-neoplastic margins, and loss of $\mathrm{CDH1}$ expression in colorectal cancer was associated with an infiltrative tumor growth pattern and lymph node metastasis $(35,36)$. A meta-analysis also identified $\mathrm{CDH} 1$ as a tumor suppressor gene that contributes to the progression of breast cancer, and suggested that $\mathrm{CDHI}$ hypermethylation could be used as a novel drug target for developing personalized therapy (37). Consistently, the 


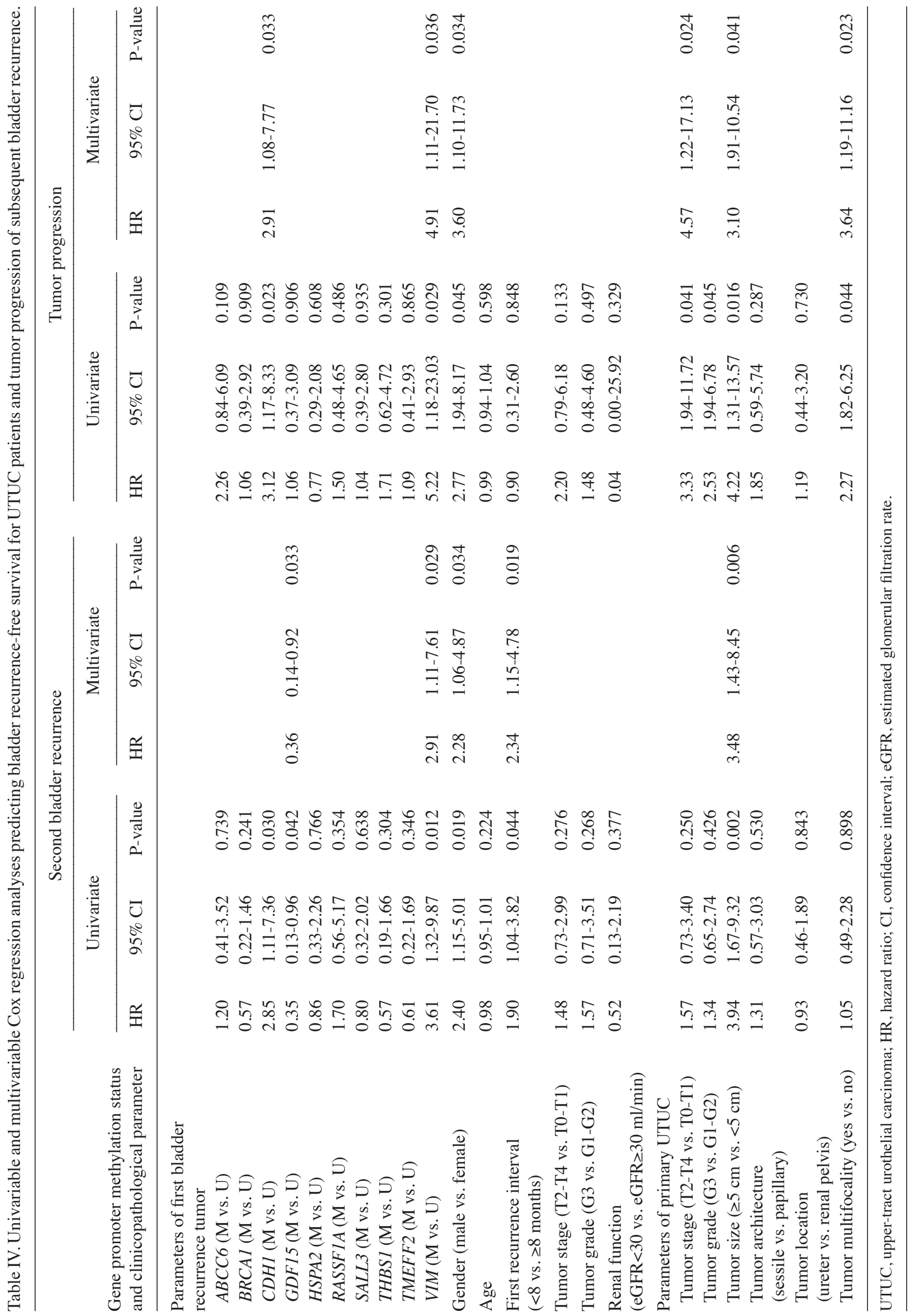


A Points

PDF15

VIM

Gender

First recurrence interval

Main tumor diameter

Total points

6-months BRFS Prob

12-months BRFS Prob

24-months BRFS Prob

36-months BRFS Prob

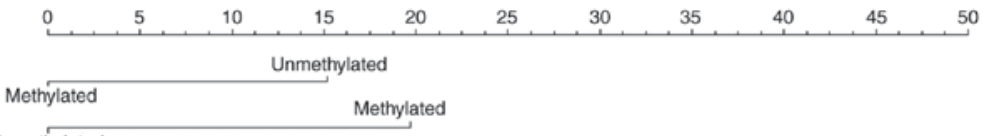

Unmethylated $\quad$ Male

Long ( $\geq 8$ months)

\begin{tabular}{|c|c|c|c|c|c|c|c|c|}
\hline \multicolumn{8}{|c|}{-ong ( $\geq 8$ months) } & \multirow[t]{2}{*}{$25 \mathrm{~cm}$} \\
\hline$<5 c$ & & & & & & & & \\
\hline 0 & 20 & 40 & 60 & 80 & 100 & 120 & 140 & 160 \\
\hline
\end{tabular}

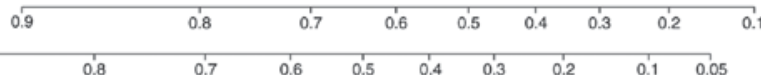

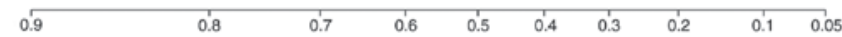

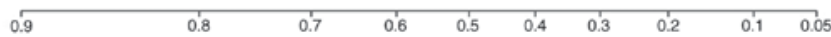
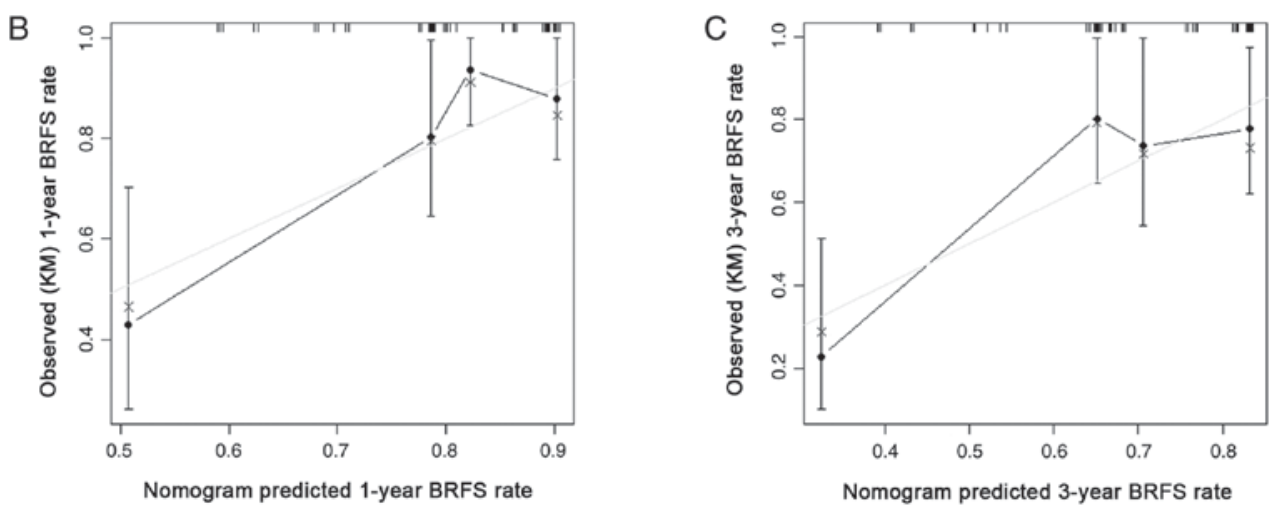

Figure 2. Nomogram for predicting the probability of BRFS after surgery for a first bladder recurrence is illustrated in (A); the c-index of this multivariate model was 0.71 (95\% CI, 0.61-0.81). The calibration plots at 1-year and 3-year follow-up for the nomogram are shown in (B) and (C), respectively. BRFS, bladder recurrence-free survival; CI, confidence interval.

A

Points

$\mathrm{CDH} 1$

VIM

Gender

Tumor stage

Main tumor diameter

Tumor multifocality

Total points

6-months PFS Prob

12-months PFS Prob

24-months PFS Prob

36-months PFS Prob

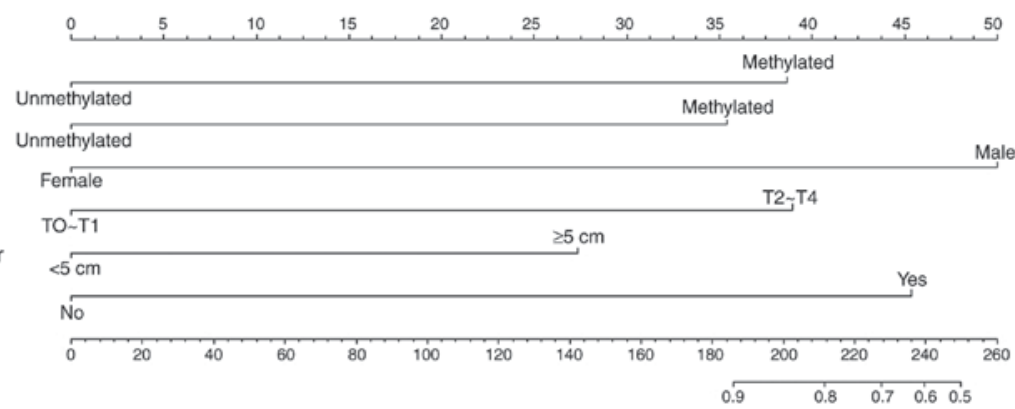

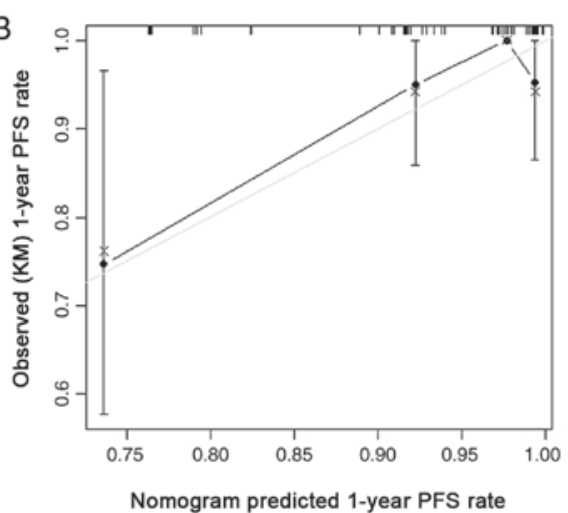

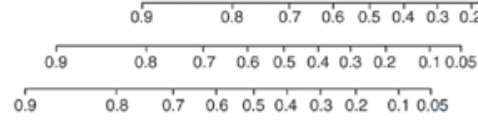

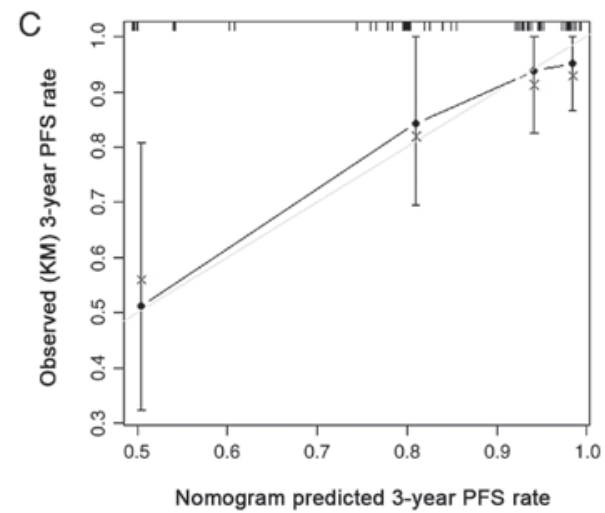

Figure 3. Nomogram for predicting the probability of PFS after surgery for a first bladder recurrence is illustrated in (A); the c- index of this multivariate model was 0.88 (95\% CI, 0.69-0.92). The calibration plots at 1-year and 3-year follow-up for the nomogram are shown in (B) and (C), respectively. PFS, progression-free survival; CI, confidence interval. 
methylation of VIM or $C D H 1$ predicted poor outcomes in the bladder after surgery for a first bladder recurrence.

Previous studies (11) have indicated that the GDF15 gene has a diverse range of cancer-specific presentations. For bladder urothelial carcinoma, GDF15 acts as a tumor suppressor gene, and methylation of GDF15 is associated with tumor invasion and progression. In the present study, we speculated that patients with GDF15 promoter methylation in the first recurrent bladder tumor may die due to the aggressive nature of the tumor before a second recurrence, and therefore unmethylated GDF15 in the first recurrent bladder tumor was a risk factor for subsequent recurrence. Compared with the predictive factors for the first recurrent bladder tumor, the predictive factors for the primary UTUC may be more easily applied in clinical decision-making. Therefore, we also analyzed the gene methylation statuses in primary UTUC; however, none showed any association with subsequent bladder outcomes after first bladder recurrence (data not shown). Nevertheless, certain clinicopathological parameters ( $\mathrm{T}$ stage, tumor size and tumor multifocality) relating to the primary UTUC had good predictive value for subsequent bladder outcomes. Prior to this study, two other studies had analyzed the bladder outcomes subsequent to surgery for the first bladder recurrence following primary UTUC. Abe et al (38) reported that $40 \%$ of primary UTUC patients experienced bladder recurrence, of whom $80 \%$ developed repeated bladder recurrence (in contrast to $37.6 \%$ in the present study), and $20 \%$ eventually showed tumor progression (compared with $18.8 \%$ in the present study). Tanaka et al (39) identified the independent prognostic factors for subsequent bladder outcomes, and the c-indexes of their multivariate models to predict second bladder recurrence and progression were 0.61 and 0.87 , respectively. By comparison, regarding the prognostic values of gene methylation, the c-indexes of our predictive models based on gene methylation status and clinical parameters for the prediction of subsequent bladder recurrence and progression were 0.71 and 0.88 , respectively.

There were several limitations of the present study, partly due to the intrinsic biases of retrospective analyses, and partly due to the small scale of our study cohort. However, while the study cohort of 85 patients was less than that of the study by Tanaka et al (39) ( $\mathrm{n}=241)$, our data were more comprehensive; in addition to routine clinical parameters, we also evaluated the methylation statuses of 10 genes in primary UTUC and in first recurrent bladder tumors. As a result, we were able to construct more accurate prognostic models to predict second bladder recurrence and tumor progression. Our predictive models will need to be validated by further research. In summary, to the best of our knowledge, this was the first study to evaluate the predictive value of clinical parameters and gene methylation status for the subsequent bladder outcomes after surgery for a first bladder recurrence following a primary UTUC treated by RNU. We speculate that our results may aid to achieve more reasonable and accurate clinical decision-making, and improve the comprehension of bladder recurrence after primary UTUC treated by RNU.

\section{Acknowledgements}

The authors gratefully acknowledge financial support from the Natural Science Foundation of Beijing (7122183 and 7152146), Natural Science Foundation of China (81172419 and 81372746) and the Clinical Features Research of Capital (no. Z151100004015173). We thank G.Y. Xiong, J. Liu, and L. Zhang for contributing their previous experience and results, and the entire staff of the Department of Urology, Peking University First Hospital for data collection support.

\section{References}

1. Rouprêt M, Babjuk M, Compérat E, Zigeuner R, Sylvester R, Burger M, Cowan N, Böhle A, Van Rhijn BW, Kaasinen E, et al: European guidelines on upper tract urothelial carcinomas: 2013 update. Eur Urol 63: 1059-1071, 2013.

2. Siegel RL, Miller KD and Jemal A: Cancer statistics, 2015. CA Cancer J Clin 65: 5-29, 2015.

3. Kauffman EC and Raman JD: Bladder cancer following upper tract urothelial carcinoma. Expert Rev Anticancer Ther 8: 75-85, 2008.

4. $\mathrm{Ku} \mathrm{JH}$, Choi WS, Kwak C and Kim HH: Bladder cancer after nephroureterectomy in patients with urothelial carcinoma of the upper urinary tract. Urol Oncol 29: 383-387, 2011.

5. Liu YQ, Lu J, Zhao L, Hou XF and Ma LL: Prognostic factors for intravesical recurrence after surgery for upper tract urothelial carcinoma in renal transplant recipients. Beijing Da Xue Xue Bao 47: 605-610, 2015 (In Chinese).

6. Rouprêt M, Babjuk M, Compêrat E, Zigeuner R, Sylvester RJ, Burger M, Cowan NC, Böhle A, Van Rhijn BW, Kaasinen E, et al: European association of urology guidelines on upper urinary tract urothelial cell carcinoma: 2015 Update. Eur Urol 68: 868-879, 2015.

7. Yamashita S, Ito A, Mitsuzuka K, Tochigi T, Namima T, Soma F, Aizawa M, Ioritani N, Kaiho Y and Arai Y: Clinical implications of intravesical recurrence after radical nephroureterectomy for upper urinary tract urothelial carcinoma. Int J Urol 23: 378-384, 2016.

8. Kulis $M$ and Esteller M: DNA methylation and cancer. Adv Genet 70: 27-56, 2010

9. Mikeska T, Bock C, Do H and Dobrovic A: DNA methylation biomarkers in cancer: Progress towards clinical implementation. Expert Rev Mol Diagn 12: 473-487, 2012.

10. Andres G, Ashour N, Sanchez-Chapado M, Ropero S and Angulo JC: The study of DNA methylation in urological cancer: Present and future. Actas Urol Esp 37: 368-375, 2013.

11. Xiong G, Liu J, Tang Q, Fan Y, Fang D, Yang K, Xie F, Zhang M, Zhang L, Liu L, et al: Prognostic and predictive value of epigenetic biomarkers and clinical factors in upper tract urothelial carcinoma. Epigenomics 7: 733-744, 2015.

12. Epstein JI, Amin MB and Reuter VR: The World Health Organization/International Society of Urological Pathology consensus classification of urothelial (transitional cell) neoplasms of the urinary bladder. Bladder Consensus Conference Committee. Am J Surg Pathol 22: 1435-1448, 1998

13. Casadio V, Molinari C, Calistri D, Tebaldi M, Gunelli R, Serra L, Falcini F, Zingaretti C, Silvestrini R, Amadori D and Zoli W: DNA methylation profiles as predictors of recurrence in non muscle invasive bladder cancer: An MS-MLPA approach. J Exp Clin Cancer Res 32: 94, 2013

14. Catto JW, Azzouzi AR, Rehman I, Feeley KM, Cross SS, Amira N, Fromont G, Sibony M, Cussenot O, Meuth M and Hamdy FC: Promoter hypermethylation is associated with tumor location, stage and subsequent progression in transitional cell carcinoma. J Clin Oncol 23: 2903-2910, 2005.

15. Maruyama R, Toyooka S, Toyooka KO, Harada K, Virmani AK, Zöchbauer-Müller S, Farinas AJ, Vakar-Lopez F, Minna JD, Sagalowsky A, et al: Aberrant promoter methylation profile of bladder cancer and its relationship to clinicopathological features. Cancer Res 61: 8659-8663, 2001.

16. Yu J, Zhu T, Wang Z, Zhang H, Qian Z, Xu H, Gao B, Wang W, Gu L, Meng J, et al: A novel set of DNA methylation markers in urine sediments for sensitive/specific detection of bladder cancer. Clin Cancer Res 13: 7296-7304, 2007.

17. Yates DR, Hupertan V, Colin P, Ouzzane A, Descazeaud A, Long JA, Pignot G, Crouzet S, Rozet F, Neuzillet Y, et al: Cancer-specific survival after radical nephroureterectomy for upper urinary tract urothelial carcinoma: Proposal and multi-institutional validation of a post-operative nomogram. Br J Cancer 106: 1083-1088, 2012.

18. Seisen T, Colin P, Hupertan V, Yates DR, Xylinas E, Nison L, Cussenot O, Neuzillet Y, Bensalah K, Novara G, et al: Postoperative nomogram to predict cancer-specific survival after radical nephroureterectomy in patients with localised and/or locally advanced upper tract urothelial carcinoma without metastasis. BJU Int 114: 733-740, 2014. 
19. Rouprêt M, Hupertan V, Seisen T, Colin P, Xylinas E, Yates DR, Fajkovic H, Lotan Y, Raman JD, Zigeuner R, et al: Prediction of cancer specific survival after radical nephroureterectomy for upper tract urothelial carcinoma: Development of an optimized postoperative nomogram using decision curve analysis. J Urol 189: $1662-1669,2013$

20. Ku JH, Moon KC, Jung JH, Jeong SH, Kwak C and Kim HH: External validation of an online nomogram in patients undergoing radical nephroureterectomy for upper urinary tract urothelial carcinoma. Br J Cancer 109: 1130-1136, 2013.

21. Hagiwara M, Kikuchi E, Tanaka N, Matsumoto K, Ide H, Miyajima A, Masuda T, Nakamura S and Oya M: Impact of smoking status on bladder tumor recurrence after radical nephroureterectomy for upper tract urothelial carcinoma. J Urol 189: 2062-2068, 2013.

22. Kusuda Y, Miyake H, Terakawa T, Kondo Y, Miura T and Fujisawa M: Gender as a significant predictor of intravesical recurrence in patients with urothelial carcinoma of the upper urinary tract following nephroureterectomy. Urol Oncol 31: 899-903, 2013.

23. Xylinas E, Colin P, Audenet F, Phe V, Cormier L, Cussenot O, Houlgatte A, Karsenty G, Bruyère F, Polguer T, et al: Intravesical recurrence after radical nephroureterectomy for upper tract urothelial carcinomas: Predictors and impact on subsequent oncological outcomes from a national multicenter study. World J Urol 31: 61-68, 2013.

24. Hamidi T, Singh AK and Chen T: Genetic alterations of DNA methylation machinery in human diseases. Epigenomics 7: 247-265, 2015 .

25. Costa VL, Henrique R, Danielsen SA, Duarte-Pereira S, Eknaes M, Skotheim RI, Rodrigues A, Magalhães JS, Oliveira J, Lothe RA, et al: Three epigenetic biomarkers, GDF15, TMEFF2 and VIM, accurately predict bladder cancer from DNA-based analyses of urine samples. Clin Cancer Res 16: 5842-5851, 2010.

26. Besaratinia A, Cockburn M and Tommasi S: Alterations of DNA methylome in human bladder cancer. Epigenetics 8: 1013-1022, 2013.

27. Kandimalla R, van Tilborg AA and Zwarthoff EC: DNA methylation-based biomarkers in bladder cancer. Nat Rev Urol 10: 327-335, 2013.

28. Habuchi T, Takahashi R, Yamada H, Kakehi Y, Sugiyama T and Yoshida O: Metachronous multifocal development of urothelial cancers by intraluminal seeding. Lancet 342: 1087-1088, 1993.

29. Habuchi T: Origin of multifocal carcinomas of the bladder and upper urinary tract: Molecular analysis and clinical implications. Int J Urol 12: 709-716, 2005.
30. Huo Y, Zheng Z, Chen Y, Wang Q, Zhang Z and Deng H: Downregulation of vimentin expression increased drug resistance in ovarian cancer cells. Oncotarget 7: 45876-45888, 2016.

31. Monteiro-Reis S, Leca L, Almeida M, Antunes L, Monteiro P, Dias PC, Morais A, Oliveira J, Henrique R and Jerónimo C: Accurate detection of upper tract urothelial carcinoma in tissue and urine by means of quantitative GDF15, TMEFF2 and VIM promoter methylation. Eur J Cancer 50: 226-233, 2014.

32. Nowakowska M, Matysiak-Burzynska Z, Kowalska K, Pluciennik E, Dominska K and Piastowska-Ciesielska AW: Angiotensin II promotes endometrial cancer cell survival. Oncol Rep 36: 1101-1110, 2016.

33. Wen L, Li J, Guo H, Liu X, Zheng S, Zhang D, Zhu W, Qu J, Guo L, Du D, et al: Genome-scale detection of hypermethylated $\mathrm{CpG}$ islands in circulating cell-free DNA of hepatocellular carcinoma patients. Cell Res 25: 1250-1264, 2015.

34. Zuo J, Wen J, Lei M, Wen M, Li S, Lv X, Luo Z, and Wen G: Hypoxia promotes the invasion and metastasis of laryngeal cancer cells via EMT. Med Oncol 33: 15, 2016.

35. Miranda E, Bianchi P, Destro A, Morenghi E, Malesci A, Santoro A, Laghi L and Roncalli M: Genetic and epigenetic alterations in primary colorectal cancers and related lymph node and liver metastases. Cancer 119: 266-276, 2013.

36. Kim SA, Inamura K, Yamauchi M, Nishihara R, Mima K, Sukawa Y, Li T, Yasunari M, Morikawa T, Fitzgerald KC, et al: Loss of CDH1 (E-cadherin) expression is associated with infiltrative tumour growth and lymph node metastasis. Br J Cancer 114: 199-206, 2016.

37. Huang R, Ding P and Yang F: Clinicopathological significance and potential drug target of $\mathrm{CDH} 1$ in breast cancer: A meta-analysis and literature review. Drug Des Devel Ther 9: 5277-5285, 2015.

38. Abe T, Shinohara N, Harabayashi T, Sazawa A, Akino T, Ishikawa S, Kubota K, Matsuno Y, Osawa T, Shibata T, et al: Pathological characteristics and clinical course of bladder tumour developing after nephroureterectomy. BJU Int 105: 1102-1106, 2010.

39. Tanaka N, Kikuchi E, Kanao K, Matsumoto K, Shirotake S, Kobayashi H, Miyazaki Y, Ide H, Obata J, Hoshino K, et al: Independent predictors for bladder outcomes after treatment of intravesical recurrence following radical nephroureterectomy in patients with primary upper tract urothelial carcinoma. Ann Surg Oncol 21: 3151-3158, 2014. 